\title{
Os docentes da Universidade Federal do Ceará e a utilização de alguns dos recursos do sistema integrado de gestão de atividades acadêmica (SIGAA)
}

Maria Naires Alves de Souza a André Jalles Monteiro ${ }^{b}$

\section{Resumo}

Nos tempos atuais, vivencia-se uma revolução da tecnologia, da comunicação e da informação. Essa revolução tem afetado, além de outras esferas da vida social, a educação, as instituições de ensino superior e a prática docente. Os sistemas de informação manipulam dados e geram informações a partir do uso de suas tecnologias. Os docentes são os profissionais que têm maior aproximação com os discentes, cabendo a eles, dentre outras funções, transitarem pelo universo da informação, transmitirem informação, possibilitarem o conhecimento e viabilizarem o fluxo de informação e comunicação com seus discentes. Com este estudo, objetiva-se investigar alguns dos usos do Sistema Integrado de Gestão de Atividades Acadêmicas (SIGAA) pelos docentes de graduação da UFC, mediante uma análise desse uso entre as diversas unidades acadêmicas da universidade. Trata-se de uma pesquisa exploratória descritiva na qual os dados principais foram coletados no banco de dados da instituição. Conforme verificado, o sistema SIGAA tem apresentado crescimento gradual de uso por parte dos docentes de graduação da UFC a cada semestre, porém sua utilização ainda não é plena. Algumas unidades acadêmicas destacam-se no uso do sistema como: FEAAC, CT e CCA.

Palavras-chave: Sistemas de informação. Tecnologia da informação e comunicação. Sistema integrado de gestão acadêmica.

\footnotetext{
a Universidade Federal do Ceará - UFC, Biblioteca. Fortaleza, Ceará, Brasil.

b Universidade Federal do Ceará - UFC, Departamento de Estatística e Matemática Aplicada. Fortaleza, Ceará, Brasil.
} 


\section{Introdução}

O desenvolvimento da humanidade embaraça-se com as tecnologias elaboradas e agregadas no transcorrer do tempo. Uma nova cultura digital surge no mundo atual e vivenciam-se transformações conceituais e paradigmáticas no que se refere às mudanças provocadas pelas novas tecnologias da informação.

Consoante evidenciado, as novas tecnologias estão cada vez mais presentes no cotidiano das Instituições de Ensino Superior (IES), no exercício e formação docente e, consequentemente, em sua prática pedagógica em sala de aula, bem como no seu relacionamento com os discentes que, cada vez mais, vêm de lares e escolas onde as tecnologias constituem uma força dominante.

Na prática educativa, as ferramentas das Tecnologias da Informação e Comunicação (TICs) favorecem novas formas e espaços de acesso à informação. Surgem perspectivas de remodelar produtos e serviços como também de ressignificar a construção do conhecimento.

Faz-se necessário conhecer o percurso e o contexto das transformações tecnológicas na educação superior, num âmbito maior, para analisar as repercussões na prática docente e a qualidade de serviços nas IES. A tecnologia não é boa nem má por si. Está implicada num contexto tanto de produção como de aplicação. Frente à tecnologia, existem diferentes propostas: os que a elogiam sem considerar seus riscos e limitações; os que a criticam sem resgatar aspectos positivos (LION, 1997).

Enfatiza-se que as tecnologias aplicadas à educação auxiliam na disseminação dos conteúdos educativos, mas, como em toda aplicação pedagógica, o acompanhamento profissional é indispensável. As tecnologias de comunicação não substituem o professor, elas são recursos tecnológicos de apoio para suas práticas nas as aulas. Segundo Moran, Masetto e Behrens (2000), há alguns pontos críticos e cruciais, sem os quais toda esta questão tecnológica em educação pode se transformar numa panaceia modernosa, mas que não vai trazer nenhum resultado significativo para o desenvolvimento educacional e cidadão dessa geração.

O Brasil depara-se, portanto, com desafios. É preciso zelar pela qualidade do ensino praticado por todas as Instituições de Ensino Superior. Para Rocha Neto e Lima, as universidades modernas têm como característica importante um bom sistema de informações que registre, como um todo, todas as atividades acadêmicas. "O sistema de informação acadêmico, ou simplesmente sistema acadêmico, é a base para uma boa gestão da universidade como um todo" (ROCHA NETO; LIMA, 2009, p. 1). 
Em âmbito local, o Sistema Integrado de Gestão de Atividades Acadêmicas (SIGAA) é a ferramenta de tecnologia da informação que a Universidade Federal do Ceará disponibiliza para sua comunidade acadêmica e no qual os procedimentos da área acadêmica são informatizados através de módulos, dentre os quais o módulo de registro e relatórios da produção acadêmica dos docentes. O SIGAA entrou em produção em 2007, tendo sido desenvolvido pela Universidade Federal do Rio Grande do Norte. Foi adquirido pela UFC por meio de convênio de cooperação técnica em 2009. Através deste sistema, os docentes acessam recursos e informações relativas à vida acadêmica e podem utilizá-lo para postar conteúdos de aula, divulgar notícias e avisos sobre as aulas, registrar a frequência das turmas, agendar avaliações, dentre outras funções. Também é por meio do SIGAA que os estudantes têm acesso aos recursos e informações sobre suas vidas acadêmicas na universidade e interagem com os professores.

No cotidiano das IES, os docentes são os profissionais que têm maior aproximação com os discentes, cabendo a eles, dentre outros papéis, transitarem pelo universo da informação, transmitirem informação, possibilitarem conhecimento e criarem estratégias de busca capazes de viabilizar o fluxo de informação e comunicação com seus discentes.

Com este estudo, objetiva-se investigar a evolução de uso do Sistema Integrado de Gestão de Atividades Acadêmicas pelos docentes de graduação da UFC. Especificamente buscar-se-á: apresentar o panorama de utilização de algumas ferramentas do SIGAA pelos docentes da UFC nos semestre letivos 2011.1; $2011.2 ; 2012.1 ; 2012.2 ; 2013.1 ; 2013.2$ e descrever como os docentes lidam com o SIGAA e como este colabora na execução das suas ações.

A pesquisa, aqui versada, possui abordagem exploratória e descritiva. Segundo Severino (2008, p. 123), a pesquisa exploratória "busca levantar informações sobre um determinado objeto, delimitando assim um campo de trabalho, mapeando as condições de manifestação desse objeto". Já para Rodrigues (2007, p. 29), uma pesquisa descritiva "é o estudo que apresenta informações, dados, inventários de elementos constitutivos ou contíguos ao objeto". O método de abordagem deu-se pelo procedimento de métodos mistos, ou seja, pesquisa qualitativa e quantitativa. $\mathrm{O}$ universo da pesquisa foram todos os docentes de graduação da UFC, cadastrados no SIGAA, vinculados a alguma turma, e que fizeram ou não uso do módulo Portal Docente nos semestres letivos entre 2011.1 a 2013.2.

A pesquisa foi empreendida no banco de dados da instituição UFC, onde se buscou identificar, dentro do módulo Portal Docente do sistema SIGAA, a evolução 
de utilização do SIGAA por intermédio das Unidades Acadêmicas, tendo por indicador as postagens de arquivos em disciplinas.

A atuação dos docentes é essencial para a interface entre a informação e os discentes na produção do conhecimento; seu desempenho é fundamental no contexto da informação educacional, porquanto está envolvido em todos os segmentos desse ciclo, desde a geração até o uso. É, pois, necessário haver profunda interlocução entre os sujeitos envolvidos no processo de geração, tratamento, disseminação, recuperação e uso das fontes informacionais, sejam elas analógicas (papel) ou digitais.

\section{Sistemas de informação}

As tecnologias da informação transformam recursos de dados em produtos de informação, os quais podem ser organizados e gerenciados dentro de um sistema. Detentor de ampla utilização, o termo "sistema" indica um grupo de elementos inter-relacionados que trabalham em busca de uma meta comum, formando um todo organizado. Informação é o resultado de dados relacionados e contextualizados.

Os sistemas de informação manipulam dados, geram informação a partir da utilização ou não de tecnologia da informação. Dado é um registro isolado, ou, ainda, são observações sobre o mundo, facilmente estruturados. Já a informação é o resultado da correlação ou organização dos dados (TJADEN, 1996). Por sua vez, o conhecimento é a informação eficaz, valiosa, focalizada em resultados, incluindo reflexão, e é de difícil estruturação (VALENTIM et al., 2003).

Para as organizações, conhecimento é componente importante à tomada de decisão. A transformação dos dados em informação é um processo. Nas palavras de Stair e Reynolds (2010, p. 5), "conhecimento é a consciência e a compreensão de um conjunto de informações e os modos como essas informações podem ser úteis para apoiar uma tarefa específica ou para chegar a uma decisão".

Consoante O'Brien (2004, p. 6), um sistema de informação "é um conjunto de pessoas, hardware, software, redes de comunicação e recursos de dados que coleta, transforma e dissemina informações em uma organização".

Segundo Laudon e Laudon (2011), sistemas de informação é um conjunto de componentes inter-relacionados trabalhando juntos para coletar, recuperar, processar, armazenar e distribuir informações com o fim de facilitar o planejamento, controle, coordenação, análise e decisão das organizações. 
Há distintos tipos de sistemas de informação bem como diferentes formas de classificar esses sistemas. Audy, Andrade e Cidral (2005) citam os seguintes sistemas de informação: sistema de processamento de transações, sistemas de informação gerencial, sistema de apoio à decisão, sistema de informação executiva, sistemas de informação como suporte à integração entre processos de negócio e funções empresarias, sistemas de informação como suporte ao processo decisório e sistemas de informação como elemento estratégico para a organização empresarial. Para os mesmos autores, um SI objetiva "disponibilizar para a organização as informações necessárias para que ela atue em um determinado ambiente" (AUDY; ANDRADE; CIDRAL, 2005, p. 110).

Um Sistema de Informação bem estruturado proporciona vantagens diversas às organizações, como otimização do fluxo informacional, integridade e veracidade de informações e mais segurança no acesso à informação.

Como observado, as IES utilizam sistema de gerenciamento acadêmico. Este sistema promove o gerenciamento de aspectos institucionais, e também dispõe de um conjunto de ferramentas de apoio ao ensino presencial. Como ferramentas de apoio ao ensino, permitem que o docente possa aperfeiçoar a comunicação com sua turma, organizar suas aulas, fornecer material de apoio on-line, dentre outras atividades.

Um dos tipos de sistemas de informação de grande relevância para as IES são os sistemas de gestão acadêmica, conforme exposto em seguida.

\section{Sistema Integrado de Gestão de Atividades Acadêmicas (SIGAA)}

Por sistemas de gestão acadêmica entendem-se sistemas de informação essenciais para o gerenciamento das atividades acadêmicas, pois permitem o controle de informações dentro das instituições, e consolidam informações relevantes para elas como dados sobre matrículas, frequência, evasão, etc.

Sistema de gestão acadêmica é uma plataforma geralmente desenvolvida em ambiente web para atender às necessidades de gestão e planejamento de uma instituição de ensino, seja esta pública ou privada, mediante otimização dos recursos físicos, humanos, materiais e financeiros (ZIUKOSKI, 2010).

O SIGAA traz um conjunto de unidades e serviços para a comunidade acadêmica, com o propósito de diminuir o tempo de operação das atividades mediante automação de atividades acadêmicas, entre estas, unifica os processos intrínsecos às atividades de ensino, pesquisa e extensão, além de outras atividades acadêmicas. 
É através deste sistema que os docentes terão acesso a todos os recursos e informações relacionadas à vida acadêmica. Por exemplo, o acompanhamento de notas e frequências nos componentes matriculados; também poderá interagir com professores e outros alunos da turma, imprimir declarações de vínculo relacionadas ao curso e também receber comunicados da coordenação do curso. Ademais, é possível ver cursos e seus currículos e obter documentos assinados digitalmente pelo sistema (UFRN, 2013a).

O Portal do Docente, ferramenta do SIGAA, reúne informações relativas aos docentes nas suas atividades acadêmicas, sejam elas de ensino, de pesquisa, de extensão ou de monitoria. Além disso, também permite que o docente cadastre informações relativas a sua produção intelectual; gerencie suas turmas através do AVA Turma Virtual; acesse aos portais os quais tem acesso (Coordenador de Lato Sensu, Coordenador de Stricto Sensu, etc.); acesse seu porta-arquivos, inscreva-se para fiscalizar vestibular e solicite compra de livros à biblioteca (UFRN, 2013b).

Assim, os docentes poderão usar o sistema para disponibilizar materiais empregados ou não em sala de aula, apresentar planejamento de aula a ser divulgado, divulgar notícias e avisos sobre as aulas, registrar frequência de aula, agendar avaliações programadas para o semestre, divulgar as notas dos alunos, dentre outras funcionalidades.

Na UFC, a utilização do SIGAA iniciou-se em agosto de 2010 no nível de ensino de pós-graduação (stricto sensu). Para o nível de ensino da graduação presencial, começou em 2011 (UFC, 2010).

Ao se logar no sistema acadêmico SIGAA, o professor/aluno verá uma página contendo as disciplinas que ele está lecionando/cursando no semestre corrente, a partir dos links presentes no nome de cada disciplina ao ambiente daquela turma. Segundo Rocha Neto e Lima (2009), o menu de navegação é dividido em diversas categorias:

- Turma: contém informações gerais sobre a turma;

- Alunos: operação de frequência e nota de alunos;

- Impressos: impressão do diário de turma e lista de frequência;

- Material: material de aula (slides, apostilas, textos, etc.);

- Atividades: opções de interatividade com os alunos;

- Configurações: políticas de permissão e exibição de dados.

Como ilustrado a seguir, o SIGAA é composto por módulos (Figura 1). 


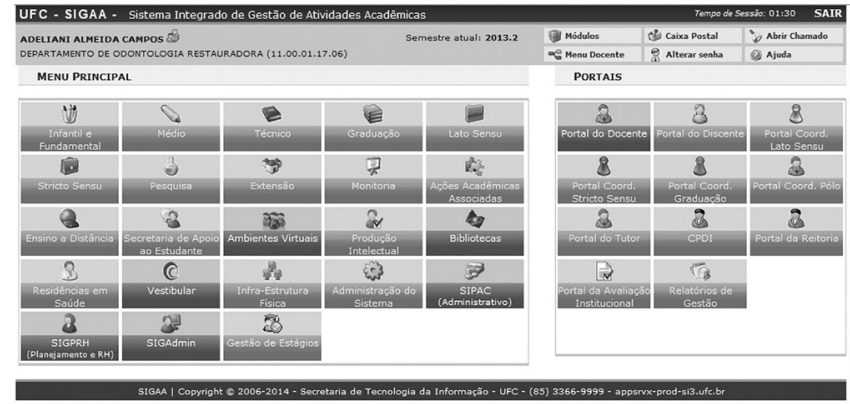

Fonte: Universidade Federal do Ceará (2013a).

Figura 1. Módulos do SIGAA - UFC.

Dentro da página Módulos do SIGAA, há o menu principal e os portais. Previamente, o usuário deverá optar por qual vínculo com a UFC (aluno, professor ou servidor técnico) pretende ter acesso. Os portais aos quais o usuário terá acesso dependerão do vínculo dele com a instituição.

Após inserir seu usuário e senha na tela inicial do SIGAA, o docente acessará sua página inicial do sistema, o Portal Docente (Figura 2).

No Portal Docente, os dados do docente são visualizados no lado direito, onde há o acesso às mensagens, edição de seu perfil, agenda de turma e demais

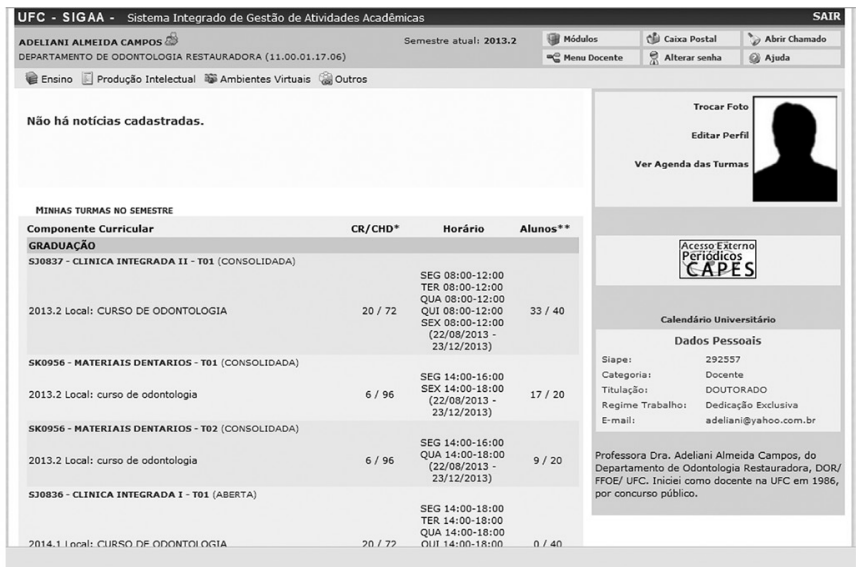

Fonte: Universidade Federal do Ceará (2013b).

Figura 2. Portal Docente. 
informações institucionais. À esquerda da tela, encontram-se as disciplinas que o docente está ministrando no semestre corrente acrescido das informações sobre local, semestre e código das mesmas.

Em cada disciplina, há o total de créditos e a carga horária atribuída. Identifica-se também o total de alunos matriculados e a capacidade total de alunos na referida turma.

Nessa mesma tela, o docente encontrará o campo "minhas turmas no semestre" no qual poderá verificar a agenda da turma no que se refere às atividades e avaliações agendadas, também se localiza a grade de horários e disposição das turmas.

O docente pode selecionar qual disciplina deseja acessar. Após a escolha, o sistema remete o docente à página da turma referente à disciplina (Figura 3 ).

Conforme mostrado na tela, a identificação da disciplina para a qual o docente optou acessar aparece na parte superior onde se visualiza o código, o nome da disciplina, o semestre letivo e a turma.

Pelo Portal Docente, o SIGAA possui um ambiente virtual denominado "turma virtual”, o qual tem por fim ser uma ferramenta de fácil acesso, voltada para a comunicação entre docentes e discentes, indo além das fronteiras da sala de aula (ROCHA NETO; LIMA, 2009).

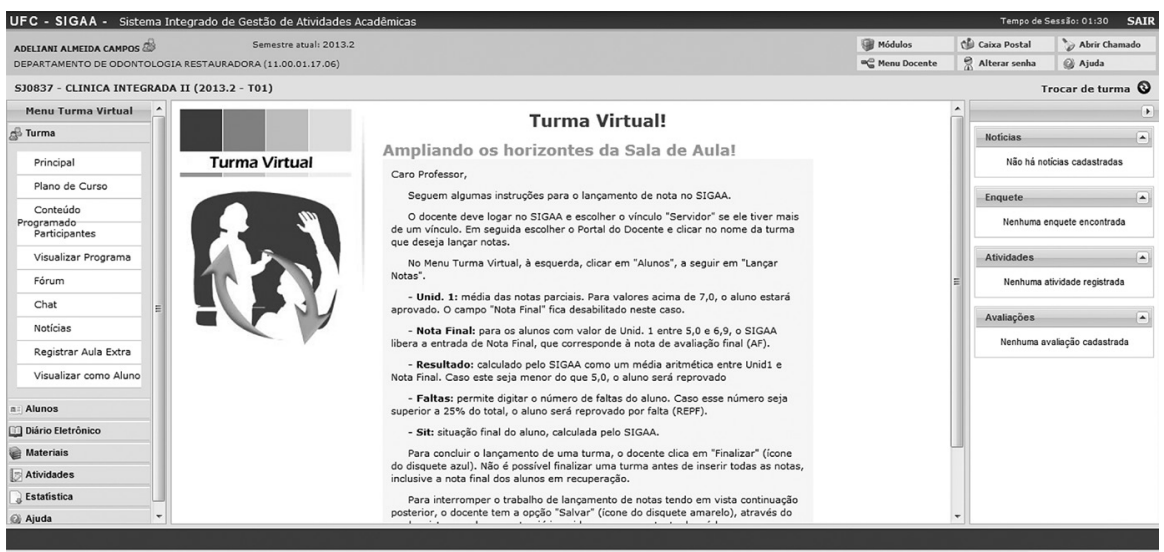

Fonte: Universidade Federal do Ceará (2013c).

Figura 3. Tela inicial de disciplina. 
A navegação no subsistema "turma virtual" é feita através do menu (lado esquerdo da tela). Na parte central da tela, encontra-se a área de trabalho e, à direita, localiza-se o painel de notícias e enquetes. De acordo com Rocha Neto e Lima (2009), o menu de navegação é dividido em diversas categorias:

- Turma: informações gerais sobre a turma e programação de aulas;

- Alunos: operações de frequência e nota de alunos;

- Impressos: impressão do diário de turma e lista de frequência;

- Material: material de aula (slides, apostilas, textos, etc.);

- Atividades: opções de interatividade com os alunos;

- Configurações: políticas de permissão e exibição de dados.

Clicando na categoria Turma (lateral esquerda da tela), o docente tem acesso a ações como:

- Principal: permite acesso à tela principal;

- Plano de curso: gerenciar plano de curso para a disciplina;

- Conteúdo programado: acesso e criação de tópicos de aulas, com um cronograma do que foi ou será visto em sala de aula;

- Participantes: página contendo a lista dos participantes da turma;

- Visualizar programa: visualiza o programa do componente curricular lançado pelo departamento ao qual o curso está vinculado;

- Fórum: fórum de discussão da turma em que poderá ser utilizado para discussões sobre os conteúdos tratados na turma;

- Chat: abertura de uma janela para bate-papo entre os participantes da turma que estiverem on-line;

- Notícias: acesso ao cadastramento de notícias;

- Registar aula extra: habilita o lançamento de tópicos de aula e frequência para aulas extras;

- Visualizar como aluno: permite que o docente tenha uma visão de como o aluno visualiza a turma virtual.

Os tópicos de aula formam a base para a organização de todo o conteúdo do subsistema "turma virtual". Através dessa tela, podem ser disponibilizados: texto do assunto visto na aula, arquivos contendo os materiais das aulas, referências bibliográfica de sites, livros, etc. e tarefas para os alunos (ROCHA NETO; LIMA, 2009).

No menu Alunos, as ações disponíveis são: lançar frequência, lançar frequência em planilha e lançar notas. 
No menu Diário Eletrônico, pode-se consultar o conteúdo programado, o diário da turma, lista de presença, mapa de frequência e total de faltas.

No menu Material, o docente poderá inserir materiais de aula, cujas opções são: conteúdo, texto formatado contendo a descrição de um assunto; inserir arquivo na turma permite adicionar arquivos em qualquer formato contendo assuntos vistos em sala de aula; porta-arquivo permite que o professor disponibilize qualquer arquivo para as turmas nas quais leciona.

No menu Atividades, o docente tem à disposição as seguintes opções: avaliações, agenda das avaliações da disciplina; enquetes, possibilidade do professor conhecer a opinião da turma sobre algum tema; fórum, permite a criação de discussões entre os participantes da turma; tarefas, oferece ao professor a oportunidade de aplicar atividades onde os alunos devem submeter arquivos que serão avaliados e comentados pelo professor.

No menu Estatísticas, o docente tem a visualização da situação dos alunos quanto às variáveis quantitativas de médias de aprovação, reprovação, etc.

O subsistema "turma virtual" do SIGAA, cuja função é servir de apoio ao ensino presencial, mostra-se uma ferramenta fundamental para a interação dos docentes e discentes.

\section{Resultados}

O sistema de gestão acadêmica SIGAA, adquirido pela UFC através de um termo de cooperação técnica com a UFRN em 2010, não apresentou problemas quanto a sua implantação e nem resistência por parte dos docentes. Ao ser implantado na UFC, seguiu, primeiramente, com alterações impactantes no sistema, no intuito de adaptá-lo às regras vigentes na UFC. Para atender às realidades da UFC, incluindo suas diferenças de gestão e regimentais em relação à criadora, UFRN, a Secretaria de Tecnologia da Informação (STI) vem promovendo diversas alterações e melhoras no sistema.

$\mathrm{Na}$ finalidade de identificar aspectos referentes à utilização, problemas e funcionalidades do Portal Docente do sistema SIGAA, procedeu-se a entrevistas abertas com os docentes da UFC que individualmente mais fazem uso do SIGAA. Com esse grupo de docentes, aplicaram-se as questões referentes à frequência de uso do SIGAA, ao tipo de postagem que costumam empreender no sistema e à opinião deles sobre suas funcionalidades. 
Dentre os docentes de graduação da UFC, selecionaram-se quatro deles que individualmente mais usam o sistema SIGAA, sendo um docente do Departamento de Engenharia Mecânica e de Produção, dois docentes do Departamento de Ciências do Solo e um docente do Departamento de Computação.

Perguntados sobre a frequência no uso do sistema SIGAA, dos quatro docentes entrevistados, dois responderam que usam diariamente; um pelo menos duas vezes por semana e um semanalmente.

Sobre o tipo de material que os docentes postam no sistema SIGAA, os quatro entrevistados postam os conteúdos das disciplinas ministradas e avisos para seu alunado. Entre os outros tipos de material postado pelos citados docentes estão: planilhas, slides e notícias, e fazer conferência com seus alunos.

Como se percebe, os docentes entrevistados fizeram uso das diversas funcionalidades que o sistema SIGAA disponibiliza para eles.

A respeito da opinião dos docentes sobre o sistema SIGAA, consoante se evidencia entre os entrevistados, o SIGAA é um sistema bom e de fácil manuseio. Assim, superadas as dificuldades iniciais de uso, torna-se fácil manuseá-lo.

Ainda como os docentes entrevistados relataram, o sistema apresenta problemas, a exemplo de dificuldade nas postagens de conteúdos como slides e símbolos matemáticos e por não ser um sistema interativo. Houve também a sugestão de que o SIGAA tenha um link que faça interação com as redes sociais. Outra dificuldade apontada pelos docentes foi em relação à infraestrutura da universidade no tocante às tecnologias, pois esporadicamente apresenta queda de rede, sistema, etc., comprometendo o trabalho de acesso ao referido sistema.

Ressalta-se que, desde a implantação do SIGAA, não houve programa de treinamento efetivo com os docentes sobre as ferramentas que o Portal Docente poderia oferecer de benefícios ou não para suas atividades pedagógicas.

Os dados coletados e analisados na pesquisa foram obtidos a partir do uso dos docentes de graduação através do Portal Docente. Neste buscou-se obter as postagens de arquivos por turmas dentro das seguintes unidades acadêmicas: FEAAC (Faculdade de Economia, Administração, Atuária e Contabilidade), CT (Centro de Tecnologia), CCA (Centro de Ciências Agrárias), IUV (Instituto Universidade Virtual), ICA(Instituto de Cultura e Arte), CC (Centro de Ciências), FACED (Faculdade de Educação), FFOE (Faculdade de Farmácia, Odontologia e Enfermagem), Faculdade de Direito, 
CH (Centro de Humanidades), Campus Sobral, IEFEs (Instituto de Educação Física e Esportes), FAMED (Faculdade de Medicina), Campus Quixadá.

\section{Postagens de arquivos por turmas de graduação - 2011.1 a 2013.2}

Atinente às postagens de arquivos diversos pelo total de turmas, as postagens de arquivos alcançaram sua média máxima, dentro do período pesquisado, no semestre de 2012.1, que ficou com média de 11,4; o total de turmas que postou arquivos equivale a $19,8 \%$ do total das turmas do referido semestre. Nos períodos seguintes, ou seja, 2012.2 e 2013.1, houve decréscimo de postagens de arquivos por turmas acadêmicas, mas não de forma expressiva, cujas médias foram de 10,8 e de 10,5. Em 2013.2, as postagens de arquivos por turmas voltaram a crescer, apresentando uma média de 11,2 por turma. As turmas que postaram arquivos representaram $0,7 \% ; 10,1 \% ; 19,8 \% ; 22,4 \% ; 25,5 \%$ e $26,4 \%$ do total de turmas dos semestres letivos de 2011.1, 2011.2, 2012.1, 2012.2 e 2013.1 e 2013.2, respectivamente, ou seja, verificou-se aumento percentual desde a implantação do sistema até o último semestre letivo pesquisado, a saber, de $0,7 \%$ a $26,4 \%$ no período (Tabela, Figuras 4 e 5).

Tabela. Distribuição dos dados da graduação no SIGAA, por semestre e de acordo com o número total de turmas sem e com postagens de arquivos - 2011.1 a 2013.2.

\begin{tabular}{lccccc}
\hline & \multicolumn{5}{c}{ Dados da Graduação } \\
\cline { 2 - 6 } Semestre & $\begin{array}{c}\text { Total de } \\
\text { turmas }\end{array}$ & $\begin{array}{c}\text { Total de } \\
\text { turmas sem } \\
\text { arquivos } \\
\text { postados }\end{array}$ & $\begin{array}{c}\text { Total de } \\
\text { turmas com } \\
\text { arquivos } \\
\text { postados }\end{array}$ & $\begin{array}{c}\text { Média de } \\
\text { arquivos } \\
\text { postados, por } \\
\text { turma }\end{array}$ & $\begin{array}{c}\text { Percentual } \\
\text { de turmas } \\
\text { com arquivos } \\
\text { postados }\end{array}$ \\
\hline 2011.1 & 4.502 & 4.469 & 33 & 4,3 & 0,7 \\
2011.2 & 3.930 & 3.538 & 392 & 9,1 & 10 \\
2012.1 & 4.115 & 3.299 & 816 & 11,4 & 19,8 \\
2013.1 & 4.145 & 3.089 & 1.056 & 10,8 & 22,4 \\
2013.2 & 3.902 & 2.872 & 1.030 & 10,5 & 25,5 \\
\hline
\end{tabular}

Fonte: Autoria própria, baseada em dados da STI/UFC (Universidade Federal do Ceará, 2013d). 


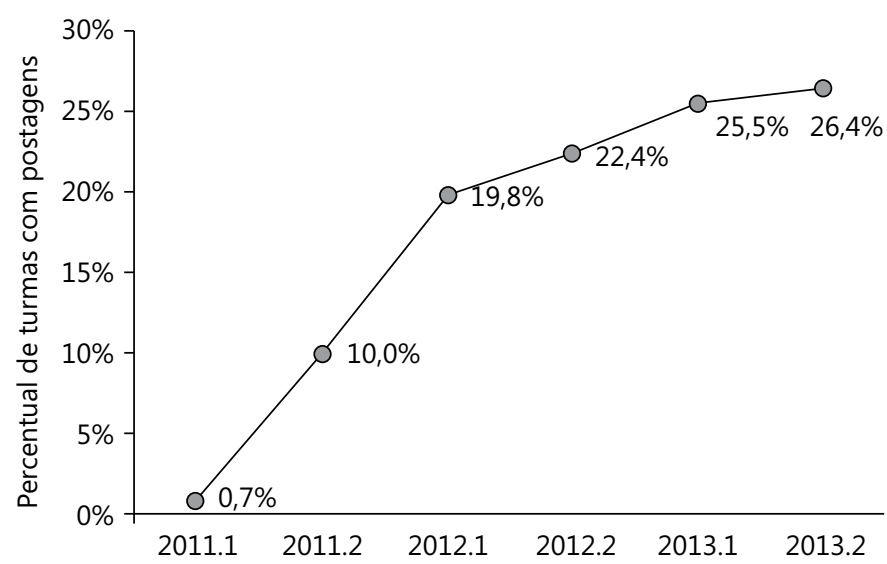

Fonte: Autoria própria, baseada em dados da STI/UFC (Universidade Federal do Ceará, 2013d).

Figura 4. Percentual de turmas com postagens de arquivos - 2011.1 a 2013.2.

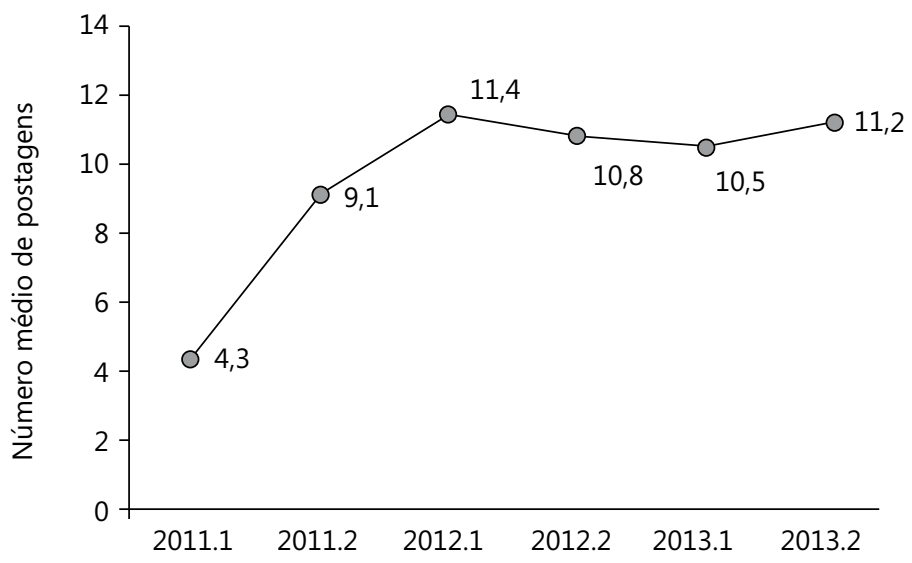

Fonte: Autoria própria, baseada em dados da STI/UFC (Universidade Federal do Ceará, 2013d).

Figura 5. Média das turmas com postagens de arquivos - 2011.1 a 2013.2.

\section{Arquivos postados por Unidades Acadêmicas - turmas de graduação - 2011.1 a 2013.2}

Conforme evidencia a Figura 6, entre as unidades acadêmicas da UFC, os destaques por postagens de arquivos por turmas são os seguintes: Faculdade de Economia, Administração, Atuária e Contabilidade (FEAAC), Centro de Tecnologia (CT) e 


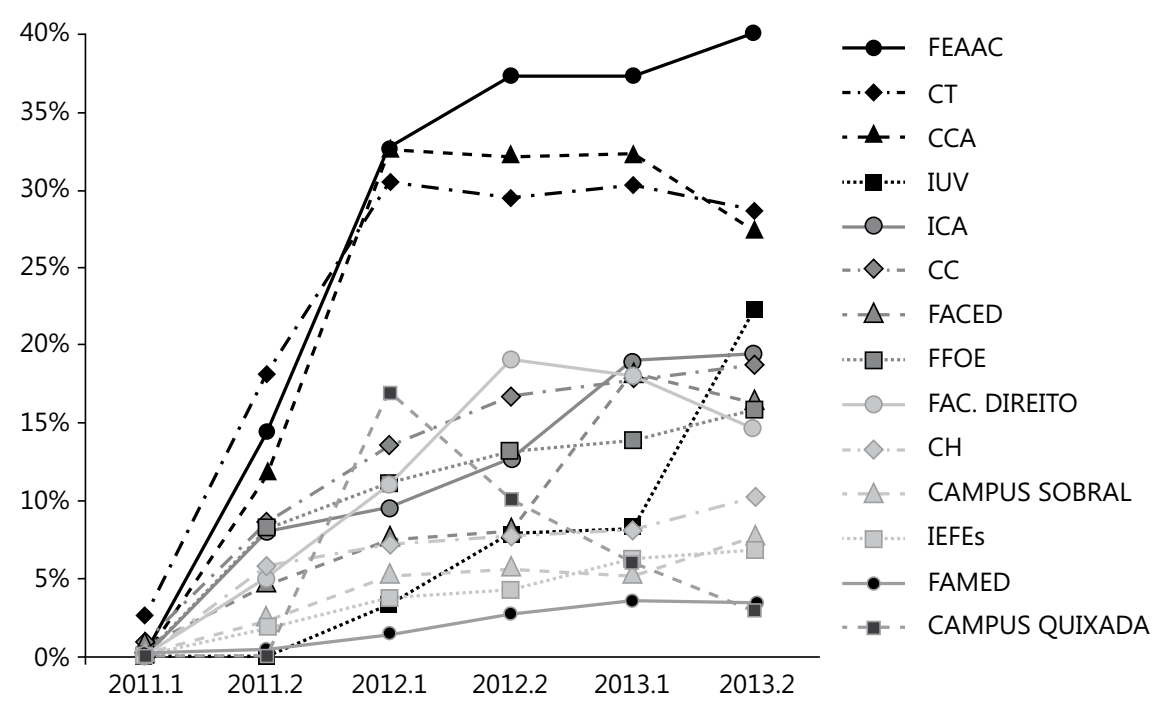

Fonte: Autoria própria, baseada em dados da STI/UFC (Universidade Federal do Ceará, 2013d).

Figura 6. Comparativo de postagens de arquivos entre as unidades acadêmicas 2011.1 a 2013.2.

Centro de Ciências Agrárias (CCA). Destaca-se também a utilização do Instituto Universidade Virtual (IUV) entre 2013.1 e 2013.2.

Outras unidades acadêmicas apresentam-se com mediano quantitativo de postagens como: o Centro de Humanidades (CH), o Campus de Sobral, O Instituto de Educação Física e Esportes (IEFEs), A Faculdade de Educação, a Faculdade de Farmácia, Odontologia e Enfermagem e a Faculdade de Direito, no decurso do tempo pesquisado, cresceram em postagem e, atualmente, então entre $10 \% \mathrm{e}$ $25 \%$ do total de arquivos postados.

No quesito de poucas postagens por turmas, sobressaem-se a Faculdade de Medicina e o Campus de Quixadá, com postagens de arquivos que não perfazem nem 5\% do total. O decréscimo de utilização desta ferramenta pelo Campus de Quixadá acentuou-se nos semestres entre 2012.1 e 2013.2.

\section{Uso do SIGAA pelos docentes de graduação - por idade}

Consoante os dados, não há correlação significativa entre a quantidade de arquivos postados e a idade do docente que posta os arquivos (Figura 7). 


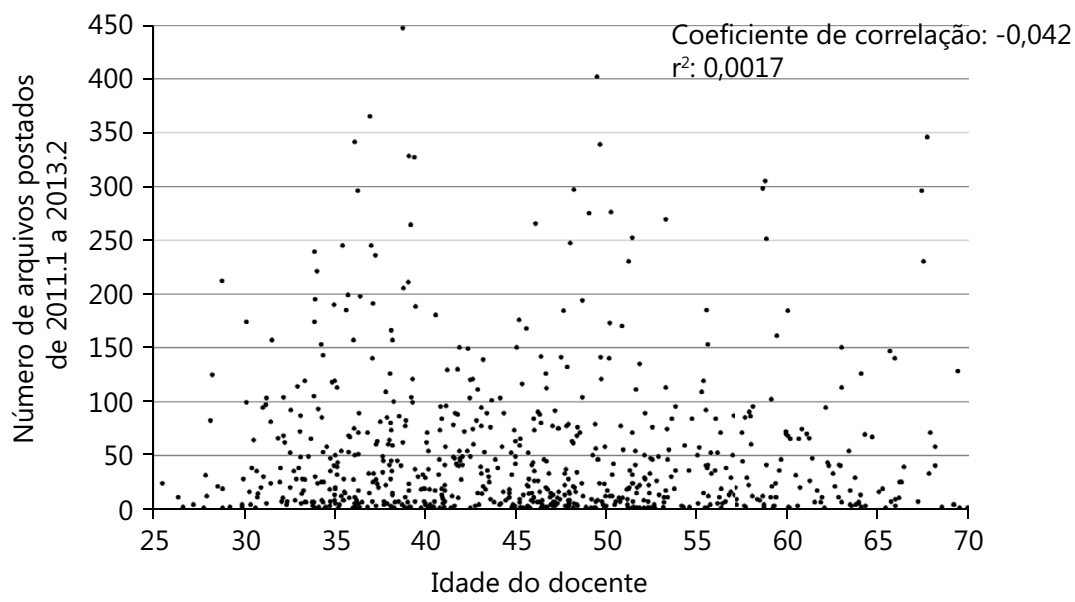

Fonte: Autoria própria, baseada em dados da STI/UFC (Universidade Federal do Ceará, 2013d). Nota: Coeficiente de correlação $=-0,042$ e $r^{2}=0,0017$.

Figura 7. Relação entre a idade do docente e o número de arquivos postados no SIGAA nos semestres de 2011.1 a 2013.2.

Com esses dados, refuta-se a hipótese segundo a qual professores mais jovens teriam tendência a postarem mais arquivos no sistema SIGAA.

\section{Conclusão}

Em um mundo de inovações tecnológicas, as tecnologias ligadas à educação ainda têm um longo caminho a percorrer. Um dos pontos a considerar é o aumento considerável de possibilidades de acesso à informação, e não se faz educação sem informação.

Nesse tema, os sistemas de gestão acadêmica são instrumentos utilizados pelas IES para o gerenciamento das atividades acadêmicas, haja vista consolidarem as informações relevantes para as mesmas instituições em referência às atividades da comunidade acadêmica. As informações ali encontradas são importantes para o planejamento de tomada de decisões que visem à melhoria da qualidade do ensino aprendizagem.

Ressalta-se que este trabalho representa uma pesquisa que expõe um recorte temporal de uso de apenas uma das ferramentas de TICs no período compreendido entre 2011.1 a 2013.2, dentre outras, que a UFC disponibiliza para sua comunidade acadêmica e, como tal, não pode ser generalizado, pois mostra um momento preciso. 
Em face dos dados expostos, é possível afirmar que: o sistema SIGAA tem apresentado crescimento de uso por parte dos docentes de graduação da UFC gradualmente a cada semestre, porém sua utilização ainda não é plena. Algumas unidades acadêmicas destacam-se no uso do sistema como: FEAAC, CT e CCA, mostrando com isso que os docentes lotados em suas subunidades acadêmicas utilizam o sistema assiduamente no referente aos arquivos postados por disciplinas ministradas. A pesquisa também acentua que não há qualquer correlação significativa entre a idade dos docentes e o uso efetivo do sistema SIGAA.

A aplicação e uso de ferramentas de tecnologia da informação parece, cada vez mais, uma prática consolidada no cotidiano da sociedade do conhecimento. $\mathrm{O}$ uso destas na educação torna tempo e lugar menos relevante no processo educativo, além de apresentar vantagens, dentre as quais, destacam-se: ser um ambiente dinâmico para transmitir eficazmente conteúdos pedagógicos e facilitar a motivação pela novidade e facilidades inesgotáveis de navegar em pesquisas. Enfatiza-se, no entanto, que as citadas ferramentas somente ajudam os docentes a realizar aquilo que eles já fazem ou desejam, poderão ser utilizadas como mediadoras e facilitadoras do processo de ensino aprendizagem. Que os professores podem vivenciar processos participativos de ensinar e aprender com ou sem tecnologia.

Evidentemente, o SIGAA pode trazer benefícios para a comunidade universitária. Entre estes: abolição da necessidade de listas de endereços eletrônicos ou outras formas de contato com os alunos; melhor gerenciamento dos professores em seus conteúdos de aula, que podem ser disponibilizados com antecedência, e, assim, os alunos, além de tomarem conhecimento prévio da aula, poderiam pesquisar em outras fontes de informação e colaborar para a produção de mais conteúdos; facilidade de acesso aos conteúdos das aulas por parte dos alunos; celeridade e eficácia no preenchimento do diário de turma pelo docente.

O docente que faz uso do instrumento Portal Docente do SIGAA poderá proporcionar aos discentes benefícios como: preparar e reforçar os alunos para o conteúdo de aula; fazer chegar, via distância, o conteúdo de aula àqueles que não puderem comparecer ao campus de forma presencial; apresentar conteúdo diverso ao que será ministrado em sala de aula; e, com conhecimento prévio do conteúdo de aula pelos alunos, o tempo de aula poderá ser utilizado para maior participação e discussões em sala. Tudo isso contribui para a melhoria na qualidade do ensino-aprendizagem.

Conforme foi possível apreender, a UFC ainda apresenta dificuldades de infraestrutura no tocante às tecnologias de informação e comunicação. Por 
conseguinte, embora o SIGAA seja um eficiente sistema integrado para atender às necessidades para as quais se destina, precisa ser aperfeiçoado como, por exemplo, no quesito interatividade e ligação com as redes sociais.

O caminho aponta para uma discussão e uma proposta de treinamentos e qualificações coletivas, na esfera da própria universidade, no contexto das unidades e subunidades acadêmicas e também por uma busca incisiva por parte dos profissionais da educação. Faz-se mister um esforço conjugado da comunidade acadêmica da UFC com o fim específico da qualificação dos profissionais da educação e, em consequência, a contribuição para melhoria no ensino-aprendizagem. 


\section{Teachers of the universidade federal do ceará and use of some of the resources of the sistema integrado de gestão de atividades acadêmica (SIGAA)}

\section{Abstract}

Currently, we are living through a revolution in technology, communication, and information. This revolution has affected not only social life but also education, institutions of higher education, and teaching methods. Information systems manipulate data and generate information through technologies. Professors are the professionals involved with students, responsible for the universe of information, sharing information, allowing the spread of knowledge, and enabling the flux of information and communication with students. In this study, we aim to investigate some uses of Sistema Integrado de Gestão de Atividades Acadêmica (SIGAA) by professors of undergraduate courses at Universidade Federal do Ceará (UFC), analyzing its use among the many university units. This is a descriptive explanatory research in which the main data were collected in the internal documents of this institution. As it could be verified, in each semester, the use of SIGAA has been gradually increasing among teachers' UFC graduation; however, its use is not yet complete. Some academic units, such as FEAAC, CT, and CCA, are distinct regarding usage of the system.

Keywords: Information systems. Communication and information technology. Integrated system of academic management.

\section{Profesores de la universidade federal de ceará y la utilización de algunos recursos de la gestión integrada de actividades académicas (SIGAA)}

\section{Resumen}

En los tiempos actuales se está experimentando una revolución en la tecnología, la comunicación y la información. Esta revolución ha afectado otras esferas de la vida social, la educación, las instituciones de educación superior y de la práctica docente. Los sistemas de información manipulan los datos y generan información de la utilización de sus tecnologías. Los profesores son profesionales que tienen una relación más estrecha con los estudiantes, permitiéndoles, entre otras funciones, transitar por el universo de la información, la transmisión de información, conocimientos y hacer posible la circulación de la información y la comunicación con sus alumnos. Este estudio tiene como objetivo investigar algunos de los usos de las actividades académicas del Sistema Integrado de Gestión SIGAA, por los profesores de la graduación UFC, mediante el análisis de dicho uso entre las unidades académicas de la universidad. Se trata de un estudio exploratorio descriptivo en el que los principales datos fueron recogidos en la institución. Como se ha señalado, el sistema SIGAA ha mostrado un crecimiento gradual en el uso por los maestros que se gradúan cada semestre en la UFC, pero aún no es completo. Algunas unidades académicas se destacan en el uso del sistema como FEAAC, CT y CCA.

Palabras clave: Sistemas de información. Tecnologías de la información y la comunicación. Sistema integrado de gestión académica. 


\section{Referências}

AUDY, J. L. N.; ANDRADE, G. K.; CIDRAL, A. Fundamentos de sistemas de informação. Porto Alegre: Bookman, 2008.

LAUDON, K. C.; LAUDON, J. P. Sistemas de informação gerenciais. São Paulo: Pearson Education do Brasil, 2011.

LIMA, G. A.; ROCHA NETO, A. F. Sistemas institucionais integrados da UFRN. Workshop de TI das IFES, 2007.

LION, C. G. Mitos e realidades na tecnologia educacional. In: LITWIN, E. (Org.). Tecnologia educacional: política, histórias e propostas. Porto Alegre: Artes Médicas, 1997.

MORAN, J. M.; MASETTO, M. T.; BEHRENS, M. A. Novas tecnologias e mediação pedagógica. Campinas: Papirus, 2000.

O'BRIEN, J. A. Sistemas de informação e as decisões gerenciais na era da internet. 2. ed. São Paulo: Saraiva, 2004.

ROCHA NETO, A. F.; LIMA, G. A. F. Turma virtual do SIGAA como ferramenta de apoio ao ensino. Natal: UFRN, 2009.

RODRIGUES, R. M. Pesquisa acadêmica: como facilitar o processo de preparação de suas etapas. São Paulo: Atlas, 2007.

SEVERINO, A. J. Metodologia do trabalho cientifico. 23. ed. São Paulo: Cortez, 2008.

STAIR, R. M.; REYNOLDS, G. W. Princípios de sistemas de informação. 9. ed. São Paulo: Cengage Learning, 2010.

TJADEN, G. S. Measuring the information age business. Technology Analysis \& Strategic Management, v. 8, n. 3, p. 233-46, 1996.

DOI:10.1080/09537329608524248

UNIVERSIDADE FEDERAL DO CEARÁ - UFC. Secretaria de Tecnologia da Informação. SI3 - SIGAA: manual de demanda e ofertas de turmas. Fortaleza: UFC, 2010.

. SIGAA - Sistema Integrado de Gestão de Atividades Acadêmicas. Menu principal. Fortaleza: UFC, $2013 \mathrm{a}$. 
UNIVERSIDADE FEDERAL DO CEARÁ - UFC. SIGAA - Sistema Integrado de Gestão de Atividades Acadêmicas. Portal docente. Fortaleza: UFC, 2013b.

. SIGAA - Sistema Integrado de Gestão de Atividades Acadêmicas. Tela inicial de disciplina. Fortaleza: UFC, 2013c.

. Secretaria de Tecnologia da Informação. Manuais e instruções. Disponível em: <http://www.sti.ufc.br/manuais-e-instrucoes $>$. Acesso em: 13 nov. 2013d.

UNIVERSIDADE FEDERAL DO RIO GRANDE DO NORTE - UFRN. Superintendência de informática. Cooperações técnicas. Disponível em: $<$ https://www.info.ufrn.br/wikisistemas/doku.php?id=supor $>$. Acesso em: 15 set. 2013a.

. Superintendência de informática. Projetos. Disponível em: $<$ http:// www.info.ufrn.br/ html/conteudo/projetos//>. Acesso em: 15 set. 2013.

. Superintendência de informática. SIGAA - Sistema Integrado de Gestão de Atividades Acadêmicas. Disponível em: $<\mathrm{http}: /$ www.info.ufrn.br/wikisistemas/ doku.php? id=suporte:sigaa:visao_geral $>$. Acesso em: 15 set. 2013b.

VALENTIM, M. L. P. et al. O processo de inteligência competitiva em organizações. DataGramaZero - Revista de Ciência da Informação, v. 4, n. 3, artigo 3, jun. 2003.

ZIUKOSKI, L. C. C. Integração do Moodle com o banco de dados institucional da UFRS. Porto Alegre: UFRS, 2010.

\section{Informações dos autores}

Maria Naires Alves de Souza: Mestre em Políticas Públicas e Gestão da Educação Superior, Universidade Federal do Ceará - UFC. Contato: marianaires@ufc.br

André Jalles Monteiro: Doutorado em Agronomia (Estatística e Experimentação Agronômica), Universidade de São Paulo - USP. Contato: jalles@ufc.br 